\title{
Angka Mortalitas dan Faktor Risiko pada Pasien Geriatri yang Menjalani Operasi Emergensi Akut Abdomen di RSUP Dr. Hasan Sadikin Bandung Tahun 2014-2015
}

\author{
Donny Prasetyo Priyatmoko, ${ }^{1}$ Reza Widianto Sudjud, ${ }^{2}$ Rudi Kurniadi Kadarsah ${ }^{2}$ \\ ${ }^{1}$ Bagian Anestesi Rumah Sakit Umum Daerah Waled, ${ }^{2}$ Departemen Anestesiologi dan Terapi Intensif \\ Fakultas Kedokteran Universitas Padjadjaran/RSUP Dr. Hasan Sadikin Bandung
}

\begin{abstract}
Abstrak
Geriatri memiliki kekhususan yang perlu diperhatikan dalam bidang anestesi dan tindakan operasi karena terdapat kemunduran sistem fisiologis dan farmakologis sejalan dengan penambahan usia. Penelitian di Yunani tahun 2007 menjelaskan bahwa angka mortalitas akibat tindakan operasi setelah usia 65 tahun menjadi 3 kali lipat dibanding dengan usia 18-40 tahun. Angka mortalitas geriatri tahun 2007 pada operasi elektif sebesar $5 \%$, sedangkan operasi emergensi sebesar $10 \%$. Tujuan penelitian ini adalah memperoleh angka mortalitas dan faktor risiko pada pasien geriatri yang menjalani operasi emergensi akut abdomen tahun 2014-2015. Tipe penelitian ini merupakan deskriptif dengan pendekatan retrospektif terhadap 180 subjek penelitian yang diambil di bagian rekam medis sejak Juli-Oktober 2016 pada pasien geriatri yang menjalani operasi emergensi akut abdomen di RSUP Dr. Hasan Sadikin Bandung tahun 2014-2015. Hasil penelitian ini memperlihatkan angka mortalitas sebesar 9\% dengan faktor penyebab mortalitas paling dominan adalah syok sepsis sebesar $50 \%$. Faktor predisposisi disebabkan oleh indeks massa tubuh $<18,5 \mathrm{~kg} / \mathrm{m}^{2}$ sebesar $56,3 \%$, diagnosis primer tumor intestinal sebesar $31,3 \%$, penyakit penyerta diabetes melitus sebesar $31,3 \%$, sepsis sebesar $93,8 \%$, hipoalbumin sebesar $56,3 \%$ dan status fisik ASA 4E sebesar $62,5 \%$. Simpulan, faktor presipitasi disebabkan oleh waktu respons penanganan $>6$ jam sebesar $93,8 \%$ dan komplikasi pascaoperasi severe sepsis disertai pneumonia sebesar $50 \%$.
\end{abstract}

Kata kunci: Akut abdomen, angka mortalitas, geriatri, operasi emergensi

\section{Mortality Rate and Risk Factors in Geriatric Patients Undergo Emergency Acute Abdomen Surgery in Dr. Hasan Sadikin General Hospital Bandung in 2014-2015}

\begin{abstract}
Specific anesthetic and surgical considerations apply for geriatric patients due to reduced physiologic functions and pharmacodynamics as the age increase. A study in Greece in 2007 shows that surgery in patients more than 65 year old has three times mortality rate than surgery in 18-40 years old patients. Geriatric mortality rate in elective surgery in 2007 is $5 \%$, while the rate for emergency surgery is $10 \%$. The purpose of this study was to identify the mortality rate and risk factors in geriatric patients underwent emergency acute abdomen surgery in 2014-2015. This was a descriptive retrospective study on 180 medical records of geriatric patients who underwent emergency acute abdomen surgery during the period of July to October 2016 in Dr. Hasan Sadikin General Hospital in 2014-2015. The results of this study showed a mortality rate of $9 \%$, with septic shock as the most dominant factor that causes mortality (50\%). The predisposing factors were body mass index $<18.5 \mathrm{~kg} / \mathrm{m} 2(56.3 \%)$, diagnosis of primary intestinal tumor (31.3\%), diabetes mellitus comorbidities (31.3\%), sepsis (93.8\%), hypoalbuminemia (56.3\%), and ASA physical status $4 \mathrm{E}(62.5 \%)$. In conclusion, the precipitation factors are caused by a response time of $>6$ hours (93.8\%) and postoperative severe sepsis complications with pneumonia (50\%).
\end{abstract}

Key words: Acute abdomen, emergency surgery, geriatrics, mortality rate

Korespondensi: Donny Prasetyo P, dr., SpAn, Bagian Anestesi Rumah Sakit Umum Daerah Waled, Jl. Prabu Kiansantang No. 4 Waled Kab. Cirebon, Tlpn.0231-661126,Email dr_donklow@yahoo.co.id 


\section{Pendahuluan}

Abad ke-20 ditandai peningkatan populasi geriatri yang bermakna, baik di negara-negara maju maupun negara-negara yang sedang berkembang. Indonesia sebagai salah satu negara sedang berkembang, dengan pelayanan kesehatan yang semakin maju, juga mengalami transisi demografi dari struktur penduduk muda ke struktur penduduk tua. Penduduk Indonesia termasuk dalam lima besar negara dengan jumlah geriatri terbanyak di dunia. Berdasar atas sensus penduduk tahun 2010, jumlah geriatri di Indonesia 18,1 juta jiwa (7,6\% dari total penduduk). Pada tahun 2014, jumlah penduduk geriatri di Indonesia menjadi 18,781 juta jiwa dan diperkirakan pada tahun 2025 jumlah akan mencapai 36 juta jiwa. Keadaan ini diakibatkan oleh semakin tinggi usia harapan hidup penduduk Indonesia, untuk laki-laki 64,17 tahun dan perempuan 65 tahun. ${ }^{1}$

Angka harapan hidup yang semakin meningkat berdampak terhadap jumlah pasien geriatri yang meningkat sehingga diperkirakan jumlah geriatri yang akan membutuhkan tindakan operasi akan meningkat pula. Tindakan operasi pada pasien geriatri dalam 20 tahun terakhir meningkat dari $19 \%$ menjadi $45 \%$. Tindakan operasi pada pasien geriatri pada awalnya dilakukan sebagai upaya terakhir dan sebagai tindakan emergensi untuk menyelamatkan nyawa pasien. Operasi emergensi berhubungan dengan angka morbiditas dan mortalitas yang semakin meningkat bila dibanding dengan operasi elektif. ${ }^{2}$

Pasien geriatri mempunyai kekhususan yang perlu diperhatikan dalam anestesi dan pembedahan karena terdapat kemunduran sistem fisiologis dan farmakologi sejalan dengan penambahan usia. Penelitian di Yunani tahun 2007 menjelaskan bahwa mortalitas akibat tindakan operasi setelah usia 65 tahun meningkat 3 kali lipat dibanding dengan usia 18-40 tahun. Angka mortalitas geriatri pada operasi elektif sebesar $5 \%$, sedangkan operasi emergensi sebesar $10 \%$. Faktor risiko mortalitas pada operasi emergensi dapat dinilai dari persiapan preoperatif, tindakan anestesi dan operasi, serta penyembuhan pascaoperasi. $^{3}$ Penyebab angka mortalitas pada geriatri yang meningkat disebabkan oleh penyakit lain yang diderita bersama-sama dengan penyakit primer yang sering kali sudah dalam keadaan lanjut sehingga meningkatkan risiko operasi. $^{3}$

Penelitian di Amerika Serikat tahun 2009 menjelaskan dari 292 pasien dengan usia diatas 65 tahun yang dilakukan operasi emergensi kolorektal didapat angka mortalitas 15\%. Faktor prognostik mortalitas pada penelitian ini adalah systemic inflamatory respon syndrome (SIRS)/sepsis, lama penanganan dari Unit Gawat Darurat (UGD) sampai ke meja operasi, kehilangan darah selama operasi, dan komplikasi pascaoperasi. $^{2}$

Penelitian di Singapura tahun 2009 menjelaskan pasien usia di atas 80 tahun yang menjalani operasi emergensi kolorektal didapatkan angka mortalitas 27,6\%. Faktor prognostik mortalitas adalah skoring American Society of Anesthesiologist (ASA). ${ }^{4}$

Penelitian di Amerika Serikat tahun 2011 juga menjelaskan dari 1.358 pasien usia di atas 80 tahun yang menjalani operasi emergensi kolorektal didapat angka mortalitas 28,9\%. Faktor prognostik mortalitas pada penelitian ini adalah memiliki riwayat penyakit paru obstruktif kronik (PPOK), penyakit jantung kongestif, kreatinin $>1,5 \mathrm{mg} / \mathrm{dL}$, SIRS/ sepsis, keganasan, dan penggunaan steroid preoperasi. $^{5}$

Penelitian di Italia tahun 2011 menjelaskan dari 215 pasien usia di atas 65 tahun yang menjalani operasi emergensi kolorektal didapat angka mortalitas $16,3 \%$. Faktor prognostik mortalitas pada penelitian ini adalah skoring ASA, riwayat penyakit neurologis, dan komplikasi kebocoran anastomosis. ${ }^{6}$

Penelitian di Jepang tahun 2012 juga menjelaskan terhadap 94 pasien usia di atas 80 tahun yang dilakukan operasi emergensi akut abdomen didapatkan angka mortalitas $16 \%$. Faktor prognostik mortalitas pada penelitian ini adalah keterlambatan datang ke rumah sakit dan skoring sistem dengan 
physiological and operative severity score for the enumeration of mortality and morbidity (POSSUM). ${ }^{7}$

Penelitian di Sumatera Utara tahun 2009 menjelaskan metode POSSUM untuk menentukan angka mortalitas terhadap 71 kasus trauma yang dilakukan tindakan laparotomi emergensi September-Desember 2008. Penelitian tersebut menyimpulkan bahwa metode ini mempunyai signifikansi dalam penerapan sebagai prediktor mortalitas. ${ }^{8}$ Pada penelitian di Yogyakarta tahun 2014, dari 370 pasien yang menjalani operasi emergensi pada pasien akut abdomen selama Januari 2009 sampai dengan Desember 2011 didapat mortalitas sebesar 12,16\%. Faktor risiko yang berhubungan signifikan terhadap mortalitas pada penelitian ini adalah sepsis dan keganasan. ${ }^{1}$

Penelitian angka mortalitas dan faktor risiko pada pasien geriatri yang menjalani operasi emergensi akut abdomen di Rumah Sakit Umum Pusat (RSUP) Dr. Hasan Sadikin Bandung selama ini belum pernah diteliti sehingga belum didapatkan data secara pasti. Penelitian ini bertujuan mengetahui angka mortalitas dan faktor risiko pada pasien geriatri yang menjalani operasi emergensi akut abdomen di RSUP Dr. Hasan Sadikin Bandung tahun 2014-2015.

\section{Subjek dan Metode}

Subjek penelitian meliputi semua status rekam medis pasien geriatri yang telah dilakukan operasi emergensi akut abdomen di ruang operasi emergensi Central Operating Theatre (COT) lantai 3 RSUP Dr. Hasan Sadikin tahun 2014-2015. Kriteria inklusi subjek adalah usia $>65$ tahun dan operasi dilakukan $<24$ jam setelah diagnosis ditegakkan.

Tipe penelitian ini merupakan penelitian deskriptif observasional yang dilakukan secara retrospektif menggunakan metode potong lintang atau crossection. Setelah mendapat persetujuan dari Komite Etik Penelitian Kesehatan RSUP Dr. Hasan Sadikin Bandung serta mendapat izin dari Bagian Pendidikan dan Penelitian Medik RSUP Dr.
Tabel 1 Karakteristik Demografik Subjek Penelitian

\begin{tabular}{lc}
\hline \multicolumn{1}{c}{ Variabel } & $\mathbf{n = 1 8 0}$ \\
\hline Usia (tahun) & \\
Mean \pm STD & $71,594 \pm 5,333$ \\
Median & 70,000 \\
Range (min.-maks.) & $66,00-91,00$ \\
Jenis kelamin & \\
Laki-laki & $123(68,3 \%)$ \\
Perempuan & $57(31,7 \%)$ \\
Berat badan (kg) & \\
Mean \pm STD & $58,455 \pm 9,3840$ \\
Median & 59,000 \\
Range (min.-maks.) & $35,00-82,00$ \\
Tinggi badan (cm) & \\
Mean \pm STD & $163,022 \pm 8,441$ \\
Median & 163,000 \\
Range (min.-maks.) & $140,00-184,00$ \\
Indeks massa tubuh $\left(\mathrm{kg} / \mathrm{m}^{2}\right)$ & \\
$<18,5$ & $40(22,2 \%)$ \\
18,5-24,99 & $108(60,0 \%)$ \\
25-29,99 & $30(16,7 \%)$ \\
$>30$ & $2(1,1 \%)$ \\
Waktu respons penanganan & \\
$<6$ jam & $118(65,6 \%)$ \\
$>6$ jam & $62(34,4 \%)$ \\
Ruang perawatan & \\
pascaoperasi & \\
ICU & $18(10,0 \%)$ \\
HCU & $15(8,3 \%)$ \\
Ruangan & $147(81,7 \%)$ \\
\hline & \\
& \\
& \\
&
\end{tabular}

Hasan Sadikin Bandung, dilakukan penilaian retrospektif terhadap 180 status rekam medis pasien geriatri yang telah menjalani operasi emergensi akut abdomen tahun 2014-2015. Setelah itu, dilakukan pengambilan data awal penelitian meliputi jenis kelamin, usia, berat badan, tinggi badan, indeks massa tubuh, diagnosis kerja, penyakit penyerta, sepsis, hipoalbumin, status fisik ASA, tindakan bedah, waktu respons penanganan, komplikasi operasi, ruang perawatan pascaoperasi, dan 
Tabel 2 Karakteristik Klinis Subjek Penelitian

\begin{tabular}{|c|c|}
\hline Variabel & $n=180$ \\
\hline \multicolumn{2}{|l|}{ Diagnosis primer } \\
\hline Perforasi gaster & $28(15,6 \%)$ \\
\hline Perforasi apendisitis & $15(8,3 \%)$ \\
\hline Tumor & $65(36,1 \%)$ \\
\hline Hernia inguinalis lateralis & $24(13,3 \%)$ \\
\hline Trauma & $1(0,6 \%)$ \\
\hline Lainnya & $47(26,1 \%)$ \\
\hline \multicolumn{2}{|l|}{ Penyakit penyerta } \\
\hline Hipertensi & $18(10,0 \%)$ \\
\hline Diabetes melitus & $6(3,3 \%)$ \\
\hline Pneumonia & $3(1,7 \%)$ \\
\hline Penyakit arteri koroner & $1(0,6 \%)$ \\
\hline Asma bronkiale & $1(0,6 \%)$ \\
\hline Penyakit paru obstruktif kronik & $1(0,6 \%)$ \\
\hline Tidak ada & $150(83,3 \%)$ \\
\hline \multicolumn{2}{|l|}{ Sepsis } \\
\hline Ya & $30(16,7 \%)$ \\
\hline Tidak & $150(83,3 \%)$ \\
\hline \multicolumn{2}{|l|}{ Hipoalbumin } \\
\hline Ya & $40(22,2 \%)$ \\
\hline Tidak & $140(77,8 \%)$ \\
\hline \multicolumn{2}{|l|}{ ASA } \\
\hline $2 \mathrm{E}$ & $109(60,6 \%)$ \\
\hline $3 E$ & $59(32,8 \%)$ \\
\hline $4 \mathrm{E}$ & $12(6,7 \%)$ \\
\hline \multicolumn{2}{|l|}{ Tindakan operasi } \\
\hline $\mathrm{LE}+$ kolostomi & $62(34,4 \%)$ \\
\hline $\begin{array}{l}\text { LE + suture primer + omental } \\
\text { patch }\end{array}$ & $29(16,1 \%)$ \\
\hline Hernioraphy tension free & $30(16,7 \%)$ \\
\hline LE + reseksi tumor & $19(10,6 \%)$ \\
\hline LE + apendektomi & $15(8,3 \%)$ \\
\hline Lainnya & $25(13,9 \%)$ \\
\hline \multicolumn{2}{|l|}{ Komplikasi pascaoperasi } \\
\hline Severe sepsis dengan pneumonia & $8(4,4 \%)$ \\
\hline Severe sepsis & $6(3,3 \%)$ \\
\hline Syok sepsis & $3(1,7 \%)$ \\
\hline Lainnya & $2(1,1 \%)$ \\
\hline Tidak ada & $161(89,4 \%)$ \\
\hline
\end{tabular}

penyebab kematian.

Pada penelitian ini analisis data kategorik dideskripsikan dengan distribusi frekuensi dan proporsi, sedangkan analisis data numerik disajikan berupa nilai dan ukuran variasi data berupa rata-rata, standar deviasi, median, dan range. Data yang diperoleh dicatat dalam formulir khusus, kemudian diolah melalui program statistical product and servise solution (SPSS) versi 21.0 for windows.

\section{Hasil}

Karakteristik demografik dari 180 subjek penelitian didapat usia rata-rata 71,594 $\pm 5,333$ tahun dengan jenis kelamin laki-laki sebagai mayoritas sebanyak 123 subjek (68,3\%). Indeks massa tubuh (IMT) pada 108 subjek $(60 \%)$ dalam status gizi normal dengan berat badan rata-rata $58,455 \pm 9 ., 3840 \mathrm{~kg}$ dengan tinggi badan rata-rata $163,022 \pm 8,441 \mathrm{~cm}$. Waktu respons penanganan mulai ditegakkan diagnosis hingga dilakukan operasi pada 118

\section{Tabel 3 Karakteristik Faktor Predisposisi pada Mortalitas Pasien Geriatri Pascaoperasi Emergensi Akut Abdomen di RSUP Dr. Hasan Sadikin Bandung Tahun 2014-2015}

\begin{tabular}{lc}
\hline \multicolumn{1}{c}{ Variabel } & $\mathbf{n = 1 6}$ \\
\hline Indeks massa tubuh $\left(\mathrm{kg} / \mathrm{m}^{2}\right)$ & \\
$<18,5$ & 9 \\
$>30$ & 1 \\
Diagnosis primer & 5 \\
Tumor & 4 \\
Perforasi gaster & 3 \\
Perforasi apendisitis & 4 \\
Lainnya & \\
Penyakit penyerta & 5 \\
Diabetes melitus & 3 \\
Hipertensi & 2 \\
Pneumonia & 15 \\
Sepsis & 9 \\
Hipoalbumin & \\
ASA & 1 \\
2E & 5 \\
3E & 10 \\
4E & \\
\hline
\end{tabular}




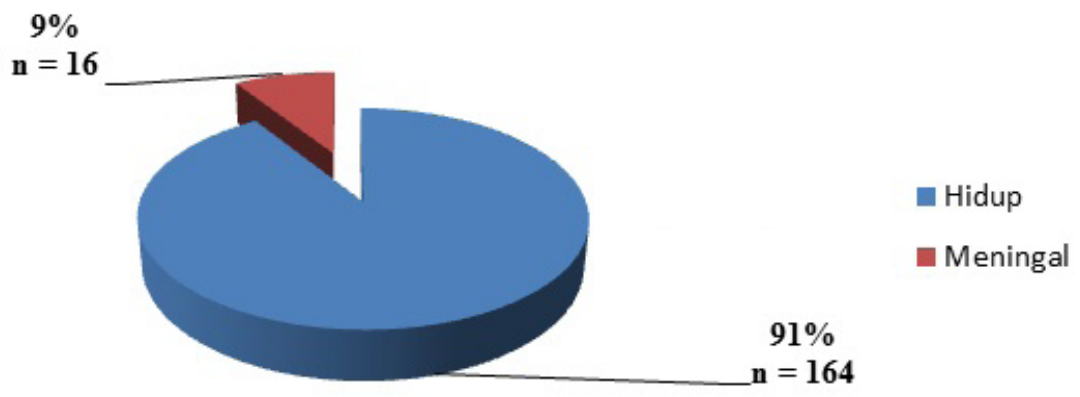

Gambar 1 Luaran Pasien Geriatri Pascaoperasi Emergensi Akut Abdomen di RSUP Dr. Hasan Sadikin Bandung Tahun 2014-2015

subjek $(65,6 \%)$ dengan hasil yang baik $<6$ jam. Perawatan pascaoperasi terhadap 147 subjek $(81,7 \%)$ dilakukan di ruang perawatan biasa (Tabel 1).

Pada Tabel 2 digambarkan karakteristik klinis 180 subjek penelitian dengan diagnosis tumor sebanyak 65 atau sebesar $36,1 \%$ sebagai diagnosis terbanyak dan tindakan operasi terbanyak laparotomi eksplorasi (LE) + kolostomi sebanyak 62 subjek $(34,4 \%)$. Hipertensi menjadi penyakit penyerta terbanyak dengan 18 subjek (10\%). Keadaan sepsis dan hipoalbumin preoperasi masingmasing sebanyak 30 subjek $(16,7 \%)$ dan 40 subjek (22,2\%). Status fisik terbanyak ASA 2E dengan 109 subjek (60,6\%). Komplikasi pascaoperasi terbanyak adalah severe sepsis dengan pneumonia sebanyak 8 subjek $(4,4 \%)$. Luaran angka mortalitas geriatri yang menjalani operasi emergensi akut abdomen di ruang operasi emergensi COT lantai 3 RSUP Dr. Hasan Sadikin periode tahun 2014-2015 adalah sebesar 9\% (Gambar 1). Penyebab mortalitas paling dominan adalah syok sepsis sebanyak 8 dari 16 pasien (Gambar 2).

Faktor predisposisi mortalitas pasien geriatri pascaoperasi emergensi akut abdomen di RSUP Dr. Hasan Sadikin Bandung tahun 2014-2015 adalah status gizi rendah (IMT $<18.5 \mathrm{~kg} / \mathrm{m}^{2}$ ) sebanyak 9 dari 16 subjek, diagnosis primer tumor intestinal sebanyak 5 dari 16 subjek, penyakit penyerta diabetes melitus 5 dari 16 subjek, sepsis preoperasi sebanyak 15 dari 16 subjek, dan hipoalbumin sebanyak 9 dari 16 subjek. Status fisik ASA 4E menjadi salah satu faktor predisposisi dominan mortalitas pada 10 dari 16 subjek (Tabel 3).

Faktor presipitasi angka mortalitas pada pasien geriatri yang menjalani operasi emergensi akut abdomen di RSUP Dr. Hasan Sadikin tahun 2014-2015 adalah waktu respons penanganan lebih dari 6 jam sebanyak 15 subjek $(93,8 \%)$ dan komplikasi
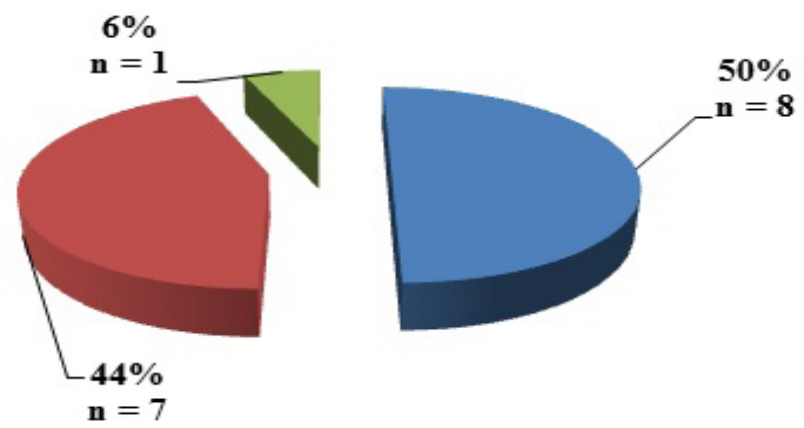

- Syok sepsis

- Respiratory faìlure !

- Pendarahan masif berulang

Gambar 2 Penyebab Mortalitas Pasien Geriatri Pascaoperasi Emergensi Akut Abdomen di RSUP Dr. Hasan Sadikin Bandung Tahun 2014-2015 
Donny Prasetyo Priyatmoko, Reza Widianto Sudjud, Rudi Kurniadi Kadarsah: Angka Mortalitas dan Faktor Risiko pada

Pasien Geriatri yang Menjalani Operasi Emergensi Akut Abdomen di RSUP Dr. Hasan Sadikin Bandung Tahun 2014-2015

pascaoperasi severe sepsis dengan pneumonia sebanyak 8 subjek (50\%; Tabel 4).

\section{Pembahasan}

Laparotomi emergensi sering dilakukan pada kasus akut abdomen di segala usia. Operasi tersebut sering dikaitkan dengan risiko morbiditas dan mortalitas yang lebih tinggi dibanding dengan operasi elektif, terutama pada pasien usia lebih dari 65 tahun dengan $50 \%$ pasien ini memiliki faktor komorbiditas yang signifikan. Mortalitas dan komplikasi pada pasien geriatri yang menjalani operasi tersebut bergantung pada faktor-faktor risiko perioperatif dan keterlambatan respons penanganan tindakan operasi dan pengobatan. ${ }^{9}$ Risiko terjadinya mortalitas tersebut diinterpretasikan sebagai hasil dari faktor predisposisi dan faktor presipitasi. Pasien geriatri dengan satu atau tanpa faktor predisposisi akan terjadi mortalitas hanya bila ada faktor presipitasi yang kuat, sedangkan pasien geriatri dengan beberapa faktor (lebih dari satu) predisposisi akan terjadi mortalitas setelah ada faktor presipitasi yang ringan saja.

Faktor usia pasien bila digunakan sebagai satu-satunya skoring untuk menentukan prognosis tindakan anestesi dan operasi terbukti tidak valid. Penelitian di Yunani tahun 2007 menjelaskan bahwa mortalitas akibat tindakan operasi setelah usia 65 tahun menjadi 3 kali lipat dibanding dengan usia 18-40 tahun. ${ }^{10}$ Penelitan di Inggris tahun 2007 menyatakan tingkat mortalitas usia di atas 74 tahun menjadi dua kali lipat dibanding dengan usia 65-74 tahun akibat tindakan operasi emergensi akut abdomen. Hal ini disebabkan pasien tersebut telah memiliki lebih banyak komorbiditas dibanding dengan pasien yang lebih muda. Simpulan penelitian ini yang dilakukan secara analisis multivarietas, usia terbukti sebagai faktor predisposisi yang lemah dalam memprediksi mortalitas, morbiditas, atau lama perawatan di rumah sakit. ${ }^{11}$

Hasil penelitian ini menunjukkan usia ratarata geriatri yang menjalani operasi emergensi akut abdomen sebesar 71,594 $\pm 5,333$ dengan rentang usia antara 66-91 tahun. Pasien geriatri yang meninggal terdapat 16 pasien dengan rentang usia 67-83 tahun. Penelitian di Denmark tahun 2014 menyatakan ada hubungan signifikan antara kenaikan usia dan jumlah angka mortalitas yang terjadi pada operasi emergensi abdomen. Hal ini dipengaruhi oleh banyak faktor predisposisi serta faktor presipitasi lain dalam meningkatkan angka mortalitas tersebut bukan hanya penilaian faktor usia tua. ${ }^{12}$

Jenis kelamin diindikasikan sebagai faktor risiko untuk mortalitas bahwa laki-laki lebih rentan daripada wanita. Hal ini disebabkan oleh berbagai faktor sehingga harapan hidup wanita lebih lama dibanding dengan laki-laki. Wanita lebih peka dalam memperhatikan kesehatan dibanding dengan laki-laki dengan mencari pusat layanan kesehatan guna mendapatkan fasilitas pengobatan dini terhadap penyakit yang diderita. Wanita memiliki hormon pelindung selama usia subur sehingga membantu dalam peredaran darah ke jantung. Laki-laki selalu dipengaruhi oleh lingkungan, risiko kerja, kecelakaan lalu lintas, pembunuhan, dan stres yang berkaitan dengan perubahan sosial ekonomi, sedangkan wanita lebih dikaitkan dengan kehidupan tradisional, menetap dianggap sebagai lingkungan yang aman. Kebiasaan merokok dan konsumsi alkohol meningkatkan risiko untuk sejumlah besar penyakit pada laki-laki. Hubungan ini mungkin akan menjadi sama atau terbalik di masa depan akibat perubahan kebiasaan pola hidup wanita. ${ }^{13}$ Keadaan ini dapat terlihat pada usia harapan hidup penduduk Indonesia, untuk laki-laki 64,17 tahun dan perempuan 65 tahun. ${ }^{1}$

Hasil penelitian ini menunjukkan jenis kelamin laki-laki sebanyak 123 atau sebesar 68,3\%. Penelitian di Singapura tahun 2015 menyatakan geriatri yang menjalani tindakan operasi emergensi akut abdomen mayoritas laki-laki sebesar $60 \% .{ }^{14}$ Penelitian di Turki tahun 2010 juga menyatakan hal yang sama, pasien geriatri laki-laki lebih banyak 53\% yang menjalani operasi emergensi akut abdomen ini dibanding dengan perempuan. ${ }^{15}$ Hal ini tidak dapat dijadikan patokan yang mendasar 
dengan perubahan budaya dan kehidupan modern sekarang ini, laki-laki dan perempuan sama rentan terhadap suatu penyakit atau bahkan terbalik.

Hasil penelitian ini didapat angka mortalitas geriatri sebanyak 16 (9\%) yang menjalani operasi emergensi akut abdomen di ruang operasi emergensi COT lantai 3 RSUP Dr. Hasan Sadikin Bandung tahun 2014-2015. Penelitian di Sumatera Utara tahun 2009 menyatakan angka mortalitas sebanyak 13 $(18,31 \%)$ pasien geriatri yang menjalani operasi emergensi akut abdomen tahun 2008 di Rumah Sakit Tempat Pendidikan (RSTP) Fakultas Kedokteran Universitas Sumatera Utara. ${ }^{8}$ Penelitian di Yogyakarta tahun 2014 menyatakan terdapat 15 (68\%) mortalitas pasien geriatri yang menjalani operasi emergensi akut abdomen tahun 2009 di RSUP Dr. Sardjito. ${ }^{1}$

Penyebab mortalitas terbanyak pada geriatri yang menjalani operasi akut abdomen tahun 2014-2015 di RSUP Dr. Hasan Sadikin adalah syok septik (50\%). Penelitian di Sumatera Utara tahun 2009 menyatakan penyebab mortalitas pasien geriatri adalah sepsis terkait dengan panperitonitis $(5,3 \%)$ dan pneumonia $(4,3 \%)^{8}$ Penelitian di Yogyakarta tahun 2014 juga menyatakan temuan yang serupa dengan komplikasi pascaoperasi pneumonia, jantung, dan sepsis menyumbang sebagian besar mortalitas pada pasien geriatri. ${ }^{1}$ Kanker dilaporkan menjadi alasan paling umum untuk mortalitas pada pasien geriatri dengan operasi emergensi akut abdomen dalam studi di Jepang tahun 2012. ${ }^{7}$

Status gizi merupakan salah satu faktor predisposisi mortalitas dengan keadaan malnutrisi yang didasarkan atas penurunan berat badan, kadar albumin rendah, dan indeks massa tubuh rendah. Indeks massa tubuh sebagai variabel kontinu tidak selalu terkait dengan mortalitas dan morbiditas setelah dibanding dengan faktor lain seperti usia, jenis kelamin, pendidikan, kelompok etnis, kanker, merokok, dan demensia. ${ }^{16}$

Hasil penelitian ini dari seluruh pasien geriatri yang mengalami mortalitas pascaoperasi emergensi akutabdomen didapat faktor predisposisi terbanyak adalah status gizi kurus dengan IMT $<18,5 \mathrm{~kg} / \mathrm{m}^{2}$ pada 9 dari 16 subjek. Selain indeks massa tubuh rendah, hipoalbumin juga menjadi faktor predisposisi malnutrisi yang akan meningkatkan angka mortalitas dengan angka kejadian sebanyak 9 dari 16 subjek. Penelitian di Amerika Serikat tahun 2014 menyatakan IMT di bawah 18,5 $\mathrm{kg} / \mathrm{m}^{2}$, kadar albumin serum rendah, status fisik ASA 4 dan Charlson score $\geq 4$ diprediksi signifikan terjadi mortalitas. ${ }^{16}$ Penelitian di Kanada tahun 2014 menyatakan IMT rata-rata pasien geriatri yang mengalami mortalitas pascaoperasi emergensi akut abdomen adalah $24,8 \mathrm{~kg} / \mathrm{m}^{2}$ dengan kadar albumin rata-rata $2,8 \mathrm{~g} / \mathrm{dL}^{17}$

Diagnosis primer akut abdomen pada geriatri dinilai menantang, sering tidak memperlihatkan gejala khas dalam menggambarkan keadaan intra-abdomen yang sebenarnya. Pasien geriatri memiliki ambang nyeri rendah atau tidak khas sehingga dapat menghilangkan tanda-tanda sepsis intra-abdomen. Laparotomi emergensi sering menyebabkan mortalitas yang signifikan dan terbukti meningkat seiring dengan semakin bertambahnya usia tua. ${ }^{18}$

Penelitian beberapa tahun terakhir menyatakan bahwa tindakan operasi abdomen pada geriatri memiliki hasil yang lebih buruk sehingga pihak rumah sakit dan tim harus memiliki strategi khusus dalam mengembangkan dan meningkatkan perawatan pasien ini. Dokter spesialis bedah tidak akan mampu melaksanakan hal ini sendiri sehingga harus berkoordinasi secara interdisiplin ilmu dengan dokter emergensi, spesialis geriatri, spesialis anestesi, spesialis perawatan kritis, perawat dengan keahlian khusus, terapis, dan ahli gizi. ${ }^{18}$

Pada penelitian ini diagnosis dengan mortalitas terbanyak adalah tumor intestinal sebanyak 5 dari 16 subjek. Penelitian di Kanada tahun 2014 menyatakan kasus obstruksi usus halus $14,7 \%$ dan hernia $11,8 \%$ menjadi diagnosis primer terbanyak pada kasus akut abdomen geriatri dengan tindakan pembuatan stoma $22,9 \%$ yang paling dominan. ${ }^{17}$ Penelitian di Denmark tahun 2014 
juga menyatakan kasus obstruksi intestinal $66 \%$ menjadi diagnosis primer terbanyak pada geriatri dengan akut abdomen diikuti dengan kasus peritonitis difus 45\% dengan tindakan operasi reseksi intestinal yang paling banyak. ${ }^{12}$

Penyakit penyerta pada geriatri memiliki dampak signifikan pada tindakan operasi dan anestesi serta membutuhkan perawatan khusus. Risiko dari tindakan anestesi lebih berhubungan dengan penyakit penyerta daripada usia itu sendiri. Oleh karena itu, penting menentukan status pasien geriatri dan menilai keadaan fisiologis pada evaluasi pemeriksaan pra-anestesi. Kondisi tersebut harus dapat dioptimalkan sebelum operasi tanpa penundaan karena dengan penundaan yang lama akan meningkatkan morbiditas dan mortalitas pascaoperasi. Diabetes melitus dan penyakit kardiovaskular sangat umum terjadi pada pasien geriatri. Komplikasi paru adalah salah satu penyebab utama morbiditas dan mortalitas pascaoperasi pada pasien geriatri. ${ }^{10}$

Hasil penelitian ini menunjukkan penyakit penyerta terbanyak pada pasien geriatri yang mengalami mortalitas pascaoperasi adalah diabetes melitus sebanyak 5 dari 16 subjek. Penelitian di Kanada tahun 2014 menyatakan hipertensi $60 \%$ sebagai penyakit penyerta paling banyak diikuti oleh PPOK 25,9\% dan diabetes melitus $20 \% .{ }^{17}$ Hipertensi, diabetes melitus, dan gangguan fungsi renal menjadi penyakit penyerta yang paling sering terjadi pada geriatri karena penurunan fungsi kapasitas organ yang berbanding terbalik dengan peningkatan usia. ${ }^{19}$

Banyak sistem penilaian telah dirancang untuk memprediksi morbiditas dan mortalitas pada pasien bedah. Sistem yang kompleks dan memerlukan pengumpulan beberapa parameter klinis mungkin tidak tersedia atau bahkan tidak dapat diterapkan untuk keadaan operasi emergensi. Akibatnya, sistem klasifikasi tersebut tidak dilakukan sebagai rutinitas praktik klinis dalam penilaian sebelum tindakan operasi. Skoring ASA merupakan salah satu penilaian yang digunakan untuk memprediksi morbiditas dan mortalitas. Hal ini menjadi tidak spesifik untuk setiap prosedur tindakan tertentu atau khusus dan juga terkait dengan berbagai pertimbangan subjektif dalam penilaian status fisik pasien. Namun, skoring ASA dinilai paling mudah dan sederhana dalam penerapan penilaian praanestesi khususnya pada kasus emergensi. ${ }^{9}$

Hasil penelitian ini menunjukkan mayoritas subjek yang mengalami mortalitas adalah ASA 4E sebanyak 10 dari 16 subjek. Hal ini sesuai dengan penelitian di Inggris tahun 2012 dan di Amerika Serikat tahun 2014 bahwa ada pasien geriatri yang menjalani operasi emergensi terutama kasus akut abdomen memiliki satus fisik ASA yang tinggi (ASA $\geq 4$ ) karena keadaan komplikasi penyakit primer maupun keadaan medis penyakit penyerta akan meningkatkan angka morbiditas maupun mortalitas. ${ }^{16,20}$

Penundaan dalam melaksanakan operasi emergensi pada geriatri sering terjadi karena terdapat komplikasi yang lebih lanjut baik dari penyakit penyerta yang dimiliki maupun penyakit primer. Pemeriksaan penunjang seperti laboratorium, rontgen toraks, CTscan di awal dapat mempercepat diagnosis akut abdomen sehingga memberikan hasil yang baik pada operasi yang akan dilakukan. Pemeriksaan penunjang tersebut membutuhkan waktu yang tidak sebentar sehingga terjadi penundaan dalam melaksanakan operasi emergensi pada pasien geriatri. Penelitian di Singapura tahun 2015 mencatat pada kasus perforasi intestinal yang menjalani operasi emergensi didapat angka mortalitas dua kali lebih tinggi pada kasus operasi yang tertunda $>6$ jam dan menjadi delapan kali lebih tinggi setelah tertunda $>24$ jam. Waktu toleransi untuk keterlambatan tersebut berbanding terbalik dengan kenaikan tingkat usia. ${ }^{14}$

Alasan penundaan operasi geriatri pada penilaian praanestesi adalah populasi geriatri sering tidak menunjukkan gejala yang khas dan kurang spesifik terhadap suatu penyakit dibanding dengan dewasa muda sehingga dibutuhkan waktu yang lebih lama dalam pemeriksaan untuk menilai kondisi dan menegakkan diagnosis. Pasien geriatri sering memiliki beberapa kondisi medis penyakit 
penyerta yang memerlukan optimalisasi sebelum dilakukan operasi sehingga akan meningkatkan waktu tunda. Penyakit penyerta ini terbukti menjadi indikator kuat prognostik negatif terhadap hasil keluaran pascaoperasi bila dibanding dengan faktor usia. ${ }^{14}$

Hasil penelitian ini menunjukkan pada kasus mortalitas didapat waktu respons penanganan $>6$ jam sebanyak 15 dari 16 subjek. Penelitian di Denmark tahun 2014 menyatakan penundaan operasi akut abdomen $>6$ jam pada geriatri meningkatkan angka mortalitas sebanyak 1,5 kali. ${ }^{12}$ Pasien yang mengalami mortalitas pascaoperasi emergensi akut abdomen hampir semua mengalami penundaan $>6$ jam. Hal ini disebabkan oleh selain penanganan penyakit penyerta yang dimiliki pasien hingga dalam kondisi optimal untuk dioperasi, penyakit primer yang dimiliki juga sudah dalam keadaan sepsis, severe sepsis, maupun syok sepsis. Waktu respons penanganan yang $>6$ jam akan membuat kondisi penyakit primer maupun penyakit penyerta tersebut semakin memburuk sehingga angka mortalitas pascaoperasi akan meningkat.

Komplikasi operasi sering terjadi pada pascaoperasi dibanding dengan intraoperasi dan hal ini dapat mulai terjadi walaupun sudah di ruang pemulihan pascaanestesi. Komplikasi yang dapat terjadi seperti infark miokardium, disritmia, henti jantung, reintubasi, ventilasi mekanik lama, pneumonia, sepsis, gangguan ginjal akut, dan perawatan pascaoperasi di ruang ICU yang tidak terencana. Pasien usia 80 tahun atau lebih, komplikasi tersebut dapat terjadi dua sampai tiga kali lebih sering dibanding dengan usia di bawah 60 tahun. Tiga puluh hari angka mortalitas meningkat secara signifikan untuk setiap dekade di atas 60 tahun. $^{21}$

Pada penelitian ini didapat geriatri yang mengalami mortalitas pascaoperasi emergensi akut abdomen memiliki komplikasi severe sepsis dengan pneumonia sebanyak 8 dari 16 subjek. Penelitian di Amerika Serikat tahun 2009 menjelaskan komplikasi yang sering terjadi pada geriatri pascaoperasi abdomen adalah syok sepsis, pneumonia, gangguan ginjal akut, dan perdarahan banyak intraoperasi. ${ }^{2}$ Penelitian di Yogyakarta tahun 2014 juga menyatakan temuan yang serupa dan komplikasi pascaoperasi pneumonia, jantung, serta sepsis menyumbang sebagian besar mortalitas pada pasien geriatri. ${ }^{1}$

Keterbatasan penelitian ini, yaitu dilakukan secara retrospektif sehingga sangat bergantung pada pendokumentasian rekam medis. Ditemukan banyak dokumentasi data faktor risiko yang diperlukan penelitian ini pada rekam medis tidak lengkap sehingga sulit untuk menilai efektivitas penilaian faktor risiko tersebut selama pra-anestesi, durante, dan pasca-anestesi.

Angka mortalitas yang didapat pada penelitian ini lebih kecil atau mungkin di-intepretasikan seolah-olah lebih baik dibanding dengan bench mark yang ada. Hal ini disebabkan oleh jumlah sampel pada penelitian ini lebih sedikit dibanding dengan bench mark sehingga tidak dapat diintepretasikan bahwa angka mortalitas pada penelitian ini lebih kecil daripada bench mark.

\section{Simpulan}

Hasil penelitian ini memperlihatkan angka mortalitas sebesar $9 \%$ dengan faktor penyebab mortalitas paling dominan adalah syok sepsis. Faktor predisposisi disebabkan oleh indeks massa tubuh $<18.5 \mathrm{~kg} / \mathrm{m}^{2}$, diagnosis primer tumor intestinal, penyakit penyerta diabetes melitus, sepsis, hipoalbumin, dan status fisik ASA 4E. Faktor presipitasi disebabkan oleh waktu respons penanganan $>6$ jam dan komplikasi pascaoperasi severe sepsis disertai pneumonia.

\section{Daftar Pustaka}

1. Hipolitus D. Faktor risiko yang berhubungan dengan mortalitas pascaoperasi darurat pada pasien akut abdomen. Yogyakarta: Subbagian Bedah Digestif RSUP Dr. Sardjito/FK UGM; 2014.

2. McGillicuddy EA, Kevin MS, Kimberly AD, Walter EL. Factors predicting morbidity and mortality in emergency colorectal 
procedures in elderly patients. Arch Surg. 2009;144(12):1157-62.

3. Griffiths R, Beech F, Brown A, Dhesi J, Foo I, Goodall J, dkk. Guidelines perioperative care of the elderly 2014. Associat Anaesthetists Great Britain Ireland. 2014;69(1):81-98.

4. Leong QM, Myint OA, Choon KH, Richard S. Emergency colorectal resections in Asian octogenarians: factors impacting surgical outcome. Surg Today. 2009;39:575-9.

5. Kwok AC, Stuart RL, Angela MB, Atul AG. Are targeted preoperative risk prediction tools more powerful? A test of models for emergency colon surgery in the very elderly. J Am Coll Surg. 2011;213(2):220-5.

6. Modini C, Romagnoli F, De Milito R, Romeo V, Petroni R, La Torre F, dkk. Octogenarians: an increasing challenge for acute care and colorectal surgeons. An outcomes analysis of emergency colorectal surgery in the elderly. Associat Coloproctol Great Britain Ireland. 2012;14:312-8.

7. Fukuda N, Joji W, Michio N, Yasuyuki S, Hiroyuki M. Factors predicting mortality in emergency abdominal surgery in the elderly. World J Emerg Surg. 2012;7(12):1-6.

8. Syafri TM. Penerapan metode POSSUM pada penderita yang menjalani laparotomi emergensi di rumah sakit tempat pendidikan FK USU tahun 2008. Medan: Subbagian Bedah Digestif Departemen Ilmu Bedah Fakultas Kedokteran Universitas Sumatera Utara Medan; 2009.

9. Abbas S, Kahokher A, Mahmoud M, Hill A. Physiologic modification of the American Society of Anaesthesiology score (ASA) for prediction of morbidity and mortality after emergency laparotomy. Intern Surg. 2008;20(2):1-9.

10. Kanonidou Z, Krystianou G. Anesthesia for the elderly. Hippokratia. 2007;11(4):175-7.

11. Rix TE, Tom B. Pre-operative risk score for the prediction of outcome in elderly people who require emergency surgery.
World Emerg Surg. 2007;2(16):1-10.

12. Svenningsen $P$, Thukirtha $M$, Nicolai BF, Morten LL, Morten BN. Increased mortality in the elderly after emergency abdominal surgery. Danish Med J. 2014;61(7):1-4.

13. Maia FOM, Yeda AOD, Maria LL, Jair LF. Risk factors for mortality among elderly people. Rev Saude Publica. 2006;40(6):1-7.

14. Ong M, Tan YG, Tan KY. Impact of surgical delay on outcome in elderly patients undergoing emergency surgery: a single centre experience. World J Gastrointest Surg. 2015;7(9):208-13.

15. Ozkan E, Mehmet MF, Ender D, Yahya 0 , Mehmet KY, Umit T. Factors affecting mortality and morbidity in emergency abdominal surgery in geriatric patients. Tourkish J Trauma Emerg Surg. 2010;16(5):439-44.

16. Rangel EL, Zara C, Olubode AO, Gally R, Stuart RL, Ali S, dkk. Mortality after emergency surgery continues to rise after discharge in the elderly: predictors of 1-year mortality. J Trauma Acute Care Surg. 2014;79(3):349-58.

17. Merani S, Judd P, Raj SP, Dareen H, Sandy LW, Rachel GK. Predictors of in-hospital mortality and complications in very elderly patients undergoing emergency surgery. World J Emerg Surg. 2014;9(43):1-7.

18. Torrance A, Susan L, Ewen A. Emergency surgery in the elderly: challenges and solutions. Open Access Emerg Med. 2015;7:55-68.

19. Jin F, Chung F. Minimizing perioperative adverse events in the elderly. $\mathrm{Br} \mathrm{J}$ Anesth. 2011;87(4):608-24.

20. Saunders DI, Muray M, Pichel AC, Varley S, Peden CJ. Variations in mortality after emergency laparotomy: the first report of the UK emergency laparotomy network. $\mathrm{Br}$ J Anaesth. 2012;109(3):368-75.

21. Hevezi ZG, Laura LH. Geriatric disoders. Dalam: Hines RL, Marschall KE, penyunting. Stoelting's anesthesia and co-existing disease. Edisi ke-6. USA: Elseiver Sanders; 2008. hlm. 642-54. 